\title{
Conflitos socioambientais em sítio Ramsar: Brutalidade e expulsões na região da Baixada Ocidental Maranhense
}

\section{Socio-environmental conflicts in Site Ramsar: brutality and expulsions in Western Lowland region of Maranhão}

Joaquim Shiraishi Neto - Doutor em Direito pela Universidade Federal do Paraná (UFPR). Professor visitante da Universidade Federal do Maranhão (UFMA), vinculado ao Programa de Pós-Graduação em Ciências Sociais (PPGCSOC). E-mail: shiraishineto@ gmail.com

Rosirene Martins Lima - Doutora em Meio Ambiente e Desenvolvimento pela Universidade Federal do Paraná (UFPR). Professora da Universidade Estadual do Maranhão (UEMA). E-mail: rosirenelima@uol.com.br

Ciro Souza Brito - Mestre em Agriculturas Amazônicas pela Universidade Federal do Pará (UFPA). Professor de Direito no Centro Universitário da Amazônia. E-mail: cirosbrito@ gmail.com

\section{Resumo}

Conflitos recentes na Baixada Ocidental Maranhense indicam uma maior pressão sobre a região, reconhecida como sítio Ramsar desde 2000. "Brutalidades" e "expulsões" são os termos aqui utilizados, por expressarem melhor a abrangência e a intensidade dos processos em curso, que devastam a biosfera e todas as formas de vida ali existentes. Este artigo objetiva refletir sobre esses processos, que ameaçam as maneiras de ser, de fazer e de viver das comunidades tradicionais, as quais constituíram um complexo sistema de uso comum das terras, das florestas, dos lagos e dos rios na região. Os resultados preliminares da pesquisa levantados em contextos diversos, a partir da observação direta e de entrevistas, apontam para a agudização dos confrontos entre o agressivo avanço do capital e a reinvenção das formas de luta das comunidades, orientada por uma maior consciência identitária.

\section{Palavras-chave}

Conflitos socioambientais. Sítio Ramsar. Comunidades tradicionais. Maranhão.

\begin{abstract}
Recent conflicts in the Baixada Ocidental Maranhense indicate greater pressure on the region, recognized as a Ramsar site since 2000. "Brutalities" and "expulsions" are the terms used here, as they better express the scope and intensity of the ongoing processes, which devastate the biosphere and all forms of live there. This article aims to reflect on these processes, which threaten the ways of being, doing and living of traditional comunities, which constituted a complex system of common use of land, florest, lakes and rivers in the region. The preliminar results of the research raised in diferente contexts, from direct observation and interviews, point to the intensification of the confrontations between the aggressive advance of capital and the reinvention of the forms of struggle of the comunities, guided by a greater identity awareness.
\end{abstract}

\section{Keywords}

Social and environmental conflicts. Ramsar site. Traditional communities. Maranhão. 


\section{INTRODUÇÃO}

Há muito as discussões sobre o melhor modelo de desenvolvimento para o Maranhão dominam os discursos políticos, que, sob a batuta de gestores e planejadores, debruçados sobre dados estatísticos e pranchetas, esboçam projetos e programas de intervenções para as diferentes regiões do estado. A pretexto de desenvolver a agropecuária, foi introduzida na região da Baixada Ocidental a criação de búfalos. Passados mais de 60 anos, os resultados revelam um enorme passivo socioambiental, agravado pela agressiva expansão do capital, que devasta a biosfera e as formas de vida ali existentes.

Os processos de devastação em curso na Baixada Ocidental Maranhense, assim como em várias partes da África e da Ásia, apresentam em comum a abrangência e a intensidade, razão pela qual se justifica o uso dos termos "brutalidades" e "expulsões" (SASSEN, 2015) ${ }^{1}$ para qualificar os agudos conflitos envolvendo os criadores de búfalos e as comunidades tradicionais nessa região do Maranhão, os quilombolas, as quebradeiras de coco, os pescadores artesanais e o povo indígena gamela ${ }^{2}$. Tais comunidades possuem múltiplas identidades, que são acionadas de acordo com os contextos. Nas duas situações observadas, as mulheres autodenominam-se ora quilombolas, ora quebradeiras de coco, podendo identificar-se como pescadoras artesanais ou mesmo como indígenas.

Com a decadência e a desagregação do sistema escravista-monocultor, essas comunidades têm desenvolvido "modelos locais de natureza" (ESCOBAR, 2016), capazes de garantir a reprodução da vida em suas diferentes formas, o controle dos territórios tradicionalmente ocupados e a equitativa distribuição dos recursos. Para Floriani (2017), tais situações estariam ligadas a uma ética socioecológica que a um só tempo enuncia os ideais de justiça ambiental e denuncia as injustiças decorrentes da desproporcional distribuição de poder sobre as bases materiais de reprodução e desenvolvimento. Aliás, as noções de "justiça ambiental” de Acselrad, Herculano e Pádua (2004, p. 10)³ e de "racismo ambiental" de Bullard $(2000,2004)$ orientam as reflexões de todo este texto.

Afirmam os primeiros autores:

No Brasil, país caracterizado pela existência de grandes injustiças, o tema da justiça ambiental vem sendo reinterpretado de modo a ampliar o seu escopo

\footnotetext{
1 Sobre esses processos na África, recomenda-se o documentário Planeta en venta, dirigido por Alexis Marant (PLANETA..., 2017).

2 Desde 2013, o povo gamela tem-se organizado para a retomada de seu território ancestral, localizado nos municípios de Viana e Matinha. Sobre esse processo, designado pela antropologia como "etnogênese", conferir o trabalho de Coelho e Almeida (2018).

3 A propósito, consultar também Acselrad (2004).
} 
[...]. As gigantescas injustiças sociais brasileiras encobrem e naturalizam um conjunto de situações caracterizadas pela desigual distribuição de poder sobre a base material da vida e do desenvolvimento. A injustiça e a discriminação, portanto, aparecem na apropriação elitista do território e dos recursos naturais, na concentração dos benefícios usufruídos do meio ambiente e na exposição desigual da população à poluição e aos custos ambientais do desenvolvimento (ACSELRAD; HERCULANO; PÁDUA, 2004, p. 10, grifo nosso).

O "racismo ambiental", afirma Bullard (2000, 2004), estaria vinculado às iniquidades, que servem de base para a exploração da terra, das pessoas e dos recursos naturais. No caso da Baixada, excluem-se todos aqueles que não se enquadram no modelo de desenvolvimento ${ }^{4}$ concebido pelo Estado ao longo das décadas. Em outros termos: certos enquadramentos epistemológicos determinam as vidas que merecem ser vividas (BUTLER, 2017); daí a naturalização do uso dos dispositivos de violência contra as comunidades tradicionais da região da Baixada Ocidental Maranhense, o que gera brutalidades e expulsões.

Os búfalos, as cercas elétricas e as formas de privatização das águas parecem justificar-se per se, na medida em que as comunidades tradicionais estão out dos enquadramentos do modelo de desenvolvimento determinado pelos governos para essa região do estado, possuidora de um ecossistema específico, designado pelo senso comum como "pantanal maranhense".

No caso, a análise dos conflitos socioambientais partiu de duas situações empiricamente observadas: a da Reserva Extrativista Enseada da Mata, no município de Penalva, e a da Sesmaria do Jardim, em Matinha. Ambos os territórios estão em processo de criação e de titulação pelo Instituto Chico Mendes de Conservação da Biodiversidade (ICMBio) e pelo Instituto Nacional de Colonização e Reforma Agrária (Incra), respectivamente, porque os grupos que lá se encontram são categorizados como população extrativista e comunidade de remanescentes de quilombo.

As situações observadas podem ser lidas como exemplares dos problemas existentes na região, decorrentes das intervenções dos governos do Maranhão. Elas representam os conflitos existentes em torno das disputas territoriais que são vividas por comunidades de quilombos, quebradeiras de coco, pescadores e indígenas.

\footnotetext{
A propósito de uma discussão crítica acerca da noção de desenvolvimento, sugere-se a leitura de Arturo Escobar (2012). O trabalho de Maristela de Paula Andrade (2017), resultado de um laudo antropológico, e o de Pedro e Sant'Ana Júnior (2018) representam exercícios convidativos para se pensar sobre o modelo de desenvolvimento em curso no Maranhão.

5 A propósito do modo como se referem a esse ecossistema específico os meios de comunicação, ver a reportagem do programa da Rede Globo Repórter Mirante sobre as belezas e os contrastes naturais da Baixada Maranhense (REPÓRTER..., 2021).
} 
O objetivo do artigo $^{6}$, portanto, é refletir sobre os processos em curso na região da Baixada Ocidental Maranhense, que ameaçam as maneiras de ser, de fazer e de viver das comunidades tradicionais, as quais constituíram um complexo sistema de uso comum das terras, das florestas, dos lagos e dos rios. Ressalte-se que, desde o final da década de 90 do século XX, os autores acompanham as transformações sociais, econômicas e ambientais na região, na condição quer de pesquisadores, quer de advogados ${ }^{7}$. Os dados aqui utilizados foram recolhidos nesse período. Para a confecção deste artigo, especificamente, os autores recorreram a um conjunto de documentos (estudos, relatórios, cartas, documentários) relativos a esses grupos, bem como a técnicas de observação direta, entrevistas semiestruturadas e conversas realizadas em distintos contextos.

O artigo está organizado em três seções, assim nomeadas: "Práticas de uso comum da terra e da natureza: uma região específica", "Búfalos e cercas elétricas: naturalização dos dispositivos de violência" e "Privatização dos usos das águas: formas de represamento para a melhoria da produção".

Na primeira seção - "Práticas de uso comum da terra e da natureza: uma região específica" -, é analisada a construção da região com base em seu contexto social, econômico e ambiental. Como parte intrínseca dessa construção, destaca-se o papel das comunidades. Elas souberam organizar esse complexo sistema de uso comum das terras, das florestas e das águas, hoje sob grave ameaça. Os "modelos locais de natureza" elaborados foram e continuam sendo imprescindíveis para a garantia da distribuição equitativa dos recursos, bem como para o controle e a defesa dos territórios tradicionalmente ocupados.

À luz das situações concretas, examinam-se os dispositivos, isto é, as técnicas e os mecanismos de controle que geram brutalidades e expulsões. O não enquadramento das comunidades na moldura de desenvolvimento estabelecida para a região tem facultado toda sorte de violência contra elas. O que se destaca é a agudez dos processos, muito mais intensos e abrangentes que em décadas passadas. Tudo isso é visto na segunda seção, intitulada "Búfalos e cercas elétricas: naturalização dos dispositivos de violência”.

\footnotetext{
6 Este artigo foi escrito no âmbito do projeto de pesquisa intitulado "Conflitos socioambientais em sítio Ramsar: modelos de natureza e direitos territoriais em disputas", com o apoio da Fundação de Amparo à Pesquisa e ao Desenvolvimento Científico e Tecnológico do Maranhão (Fapema), conforme o Edital 035/2018.

7 Na condição de pesquisador do Projeto Nova Cartografia Social da Amazônia (PNCSA), elaborei mapa, fascículo e livro (ALMEIDA; SHIRAISHI NETO; MARTINS, 2005). Como advogado, realizei o estudo da situação fundiária para a criação da Resex Enseada da Mata (SHIRAISHI NETO, 2011). Brito (2018) fez a sua pesquisa de mestrado na comunidade quilombola Sesmaria do Jardim.
} 
A terceira seção - "Privatização dos usos das águas: formas de represamento para a melhoria da produção" - focaliza as intervenções mais recentes na região, as quais, a pretexto da melhoria do sistema de produção local, introduziram as atividades de piscicultura e de carcinicultura.

Os resultados preliminares da pesquisa apontam para uma agudização dos confrontos, acompanhada de uma maior tomada de consciência da questão identitária na região. Contudo, o momento vivido pelo país, com o desmonte das políticas territoriais e ambientais, coloca em questão as próprias estratégias adotadas por essas comunidades.

\section{PRÁTICAS DE USO COMUM DA TERRA E DA NATUREZA: UMA REGIÃO ESPECÍFICA}

A Baixada Ocidental Maranhense faz parte do que tem sido designado pelos intérpretes do Maranhão como área de "colonização antiga". Ela difere das áreas de colonização espontânea do estado, que sofreram a penetração das frentes nordestinas em busca de terras férteis, fugindo das secas do Nordeste e das formas de imobilização da força de trabalho (VALVERDE, 1957; VELHO, 1981).

$\mathrm{Na}$ década de 60 do século XX, as medidas do governo do Maranhão para as áreas de fronteira destinavam-se a modernizar o setor agrícola do estado e a resolver as tensões existentes na região de colonização antiga (ALMEIDA; MOURÃO, 1976).

Justamente na área de colonização antiga do estado, as transformações da estrutura agrária decorreram do que foi denominado decadência e desagregação do sistema escravista-monocultor exportador no final do século XIX e início do século XX (ANDRADE, 1999; SÁ, 2007). Quando os preços da cana-de-açúcar e do algodão despencaram no mercado internacional, os grandes proprietários de terras na região venderam, doaram ou mesmo abandonaram os seus domínios em favor dos seus ex-escravos e dos trabalhadores livres (ALMEIDA, 1989).

A derrocada do sistema gerou a formação de um campesinato livre (SÁ, 2007) que, à margem, passou a se dedicar à agricultura de base familiar nas grandes propriedades de terras na condição de ocupantes. A situação dos autodenominados "caboclos da Terra de Índios" na região, segundo Paula Andrade (1999), não se enquadraria nesse esquema explicativo, já que a hipótese levantada pela autora é de que a constituição do grupo por ela estudado "[...] teria se iniciado a partir da segunda metade do século XVII, quando da 'domesticação' dos gamelas. Não foram escravos ou agregados das grandes fazendas, que nelas permaneceram depois da decadência” (ANDRADE, 1999, p. 76). 
Lembra O’Dwyer (2007) que a emergência do campesinato negro comunal na Baixada Ocidental Maranhense foi analisada inicialmente por Sá, cujas reflexões foram reelaboradas e inseridas por Alfredo Wagner Berno de Almeida em uma discussão mais ampla, envolvendo os sistemas de uso comum na estrutura agrária brasileira.

Ao sistematizar os dados no Brasil, Almeida (1989) constata que as situações estudadas por Sá e Paula Andrade na Baixada, assim como outras - a dos faxinais no Sul do Brasil, por exemplo, examinadas por Horácio Martins Carvalho (1984) -, foram ignoradas nas reflexões e políticas agrárias, embora extremamente relevantes para os grupos sociais, já que lhes possibilitaram a garantia e o controle dos territórios. Na Baixada Ocidental Maranhense, Paula Andrade (1999) sublinha que as práticas sociais de uso comum constituíram estratégias utilizadas no período dos conflitos, como forma de defesa dos territórios tradicionalmente ocupados.

As garantias de produção e de reprodução desse campesinato negro comunal, como referiu O’Dwyer (2007), decorreram de uma situação econômica específica e de um espaço com condições ecológicas bastante particulares, descritas em vários trabalhos (ABREU, 1931; LOPES, 1970²).

Os referidos autores maranhenses descrevem a Baixada Ocidental como uma enorme porção de terras alagadas, formada por lagos e rios, que se estendem por vários municípios do estado, todos situados na pré-Amazônia maranhense. Em sua obra $\mathrm{Na}$ Terra das Palmeiras, Froes Abreu destaca: "[...] Os campos da baixada constituem uma das feições que definem a terra maranhense e a tornam semelhante ao typo amazônico; os campos do litoral são um simile dos do baixo Amazonas e Marajo" (ABREU, 1931, p. 11, grifo nosso).

Diante de tais feições ecológicas, a Baixada foi decretada Área de Proteção Ambiental (APA) por meio do Decreto Estadual n. ${ }^{\circ} 11.900$, de 11 de fevereiro de 1991 (MARANHÃO, 1991a), e, em 2000, reconhecida como sítio Ramsar. No Maranhão, outras duas áreas também foram reconhecidas pela Convenção de Ramsar: a APA das Reentrâncias Maranhenses, em 30 de novembro de 1993, contigua à APA da Baixada, em direção ao litoral (ver Mapa 1), e o Parque Estadual Marinho do Parcel de Manuel Luís, incluindo os Baixios do Mestre Álvaro e Tarol, em 29 de fevereiro de $2000^{9}$.

De 1971, a Convenção de Ramsar (BRASIL, 1996) é um tratado internacional assinado pelo Brasil, cujo objetivo é promover a conservação e

\footnotetext{
Sobre uma antropogeografia da região da Baixada Ocidental Maranhense, ler a descrição de Raimundo Lopes (1970, p. 120-147).

9 A relação dos sítios Ramsar no Brasil pode ser consultada em Brasil ([2018?]).
} 
o uso racional das zonas úmidas. A definição de zonas úmidas adotada por ela é bastante abrangente, incluindo ambientes de água doce, salobra ou salgada. Segundo o Ministério do Meio Ambiente, essas zonas são importantes:

[...] oferecem diversos serviços (controle de enchentes, purificação de água, retenção de carbono, proteção da linha de costa, etc.) e produtos (solo rico para agricultura, água potável, fibras para utensílios e construção, combustível, recursos pesqueiros) e, portanto, são vistas como áreas de interesse estratégico tanto do ponto de vista ambiental como do desenvolvimento socioeconômico (BRASIL, [entre 2007 e 2010], p. 5).

\section{Mapa 1 - Região da Baixada Ocidental Maranhense}

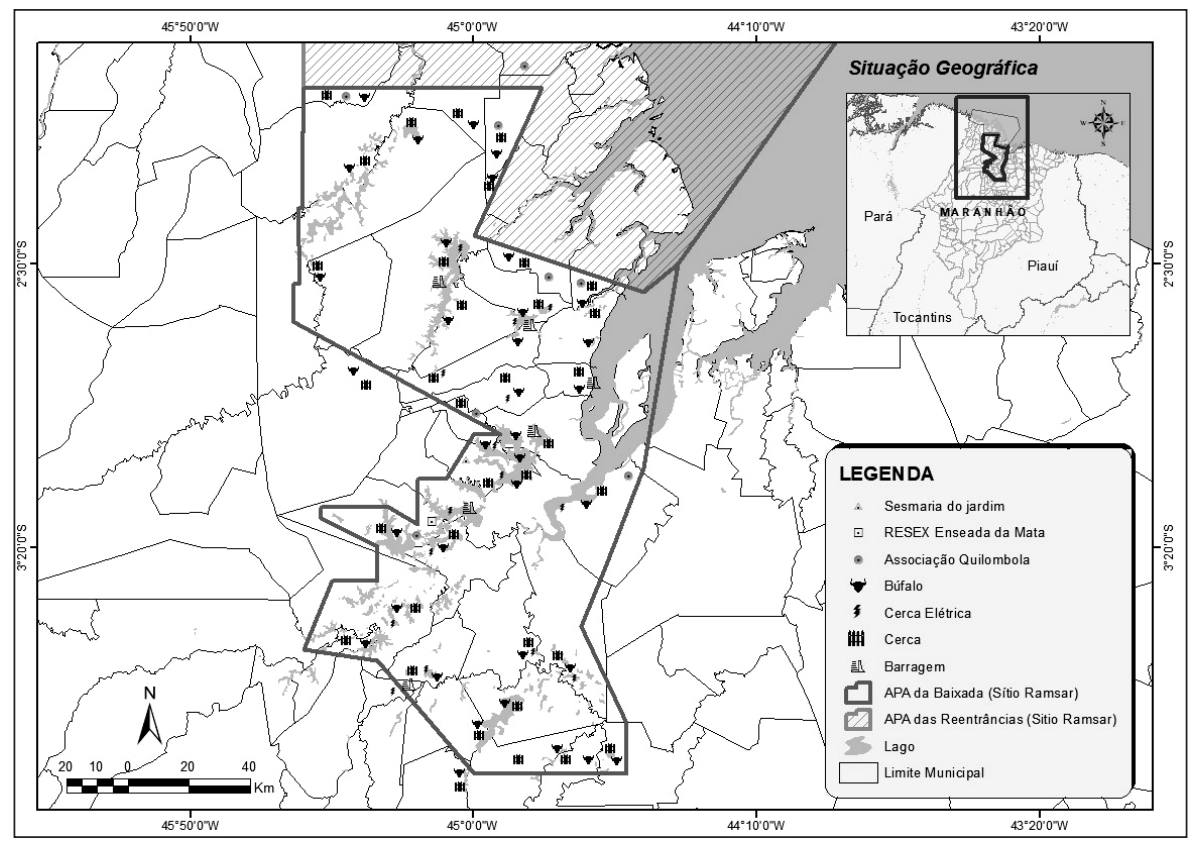

Fonte: Grupo de Pesquisa Cidade, Território e Meio Ambiente (Citema), 2018.

Tais são as condições que permitiram a constituição da Baixada Ocidental Maranhense como uma região específica (SÁ, 2007). Aqui nos atrevemos a afirmar que essa região forma uma imensa unidade territorial de comunidades tradicionais, onde até pouco tempo atrás os cercos não se fechavam, a exemplo dos cerrados maranhenses. De sorte, observa-se uma forte relação entre as diversas dimensões de vida das comunidades, que se relacionam entre si, baseadas em critérios de solidariedade e de reciprocidade.

$\mathrm{Na}$ Reserva Extrativista Enseada da Mata e na Sesmaria do Jardim, foi observada detidamente a maneira como são organizadas a lida e as atividades 
produtivas. Elas associam a roça - cultivada nos períodos do verão e do inverno, diferentemente de outras regiões do próprio estado - às práticas extrativistas. A pesca artesanal ocorre nos chamados "puções" ou "poções"10, que se formam nos campos naturais inundáveis constituídos pela área ciliar ${ }^{11}$ e pelos campos cobertos ${ }^{12}$.

Os chamados "puções" ou "poções" são locais mais profundos que se formam nos campos naturais inundáveis onde a água é limpa - espécie de laguinhos. Segundo dona Maria Nice Machado Aires, são ideais para as atividades da pesca realizadas durante todo o período do ano, no verão e no inverno, daí os cuidados em manter os puções ou poções sempre limpos para que os peixes possam adequadamente se reproduzir. Esse tipo de interação está inserido em uma racionalidade que revela a profunda relação de respeito entre as comunidades e a natureza. Como salientou Vandana Shiva, “[...] a terra dá presentes aos homens que, em troca, devem mostrar diligência para com ela, não abusando de sua generosidade" (SHIVA, 2005, p. 206, tradução nossa).

Independentemente da localização dos puções ou poções - mais próximos ou distantes de determinadas comunidades - ou do nome que os identificam ${ }^{13}$, o seu uso é comum às famílias: "Ele é de todo mundo, as pessoas só pegam o peixe para o almoço" (informação verbal) ${ }^{14}$. Tais práticas socioambientais, que se circunscrevem às atividades de pesca nos campos realizadas pelos moradores das comunidades, demonstram um cuidado absoluto e o domínio sobre os ciclos da natureza diante do frágil ecossistema, associando o saber e o fazer a um senso de justiça ambiental, uma vez que é garantido a todos os moradores o direito de acesso e de uso comum dos recursos de modo indistinto e na medida de suas capacidades e necessidades. Dito de outro jeito, ninguém pesca o peixe para acumular ou enriquecer.

10 É interessante observar que, na literatura levantada, essa questão dos puções ou poções passou despercebida pelos pesquisadores, que na época estavam ocupados com outras questões. Quase não há referência a essa prática, que tem as suas particularidades ancoradas em um saber prático, construído coletivamente.

11 A área ciliar fica na beira do campo, ela enche e seca durante o ano, acompanhando os ciclos do inverno e do verão. Nela, é possível encontrar uma diversidade de animais (capivara, paca, jacaré, tamanduá etc.) e madeiras (marajá, cambucá, pitara, caju-do-mato, pau-d’arco, fava etc.).

12 Os campos cobertos, por sua vez, mantêm-se alagados durante todo o ano. Vários animais escondem-se ali (cobras, jacarés, poraquês etc.). A mata dos campos cobertos (juçara, bacaba, pequi, bacuri etc.) tem uma função importante na dieta das comunidades.

13 Geralmente, o pução ou poção leva o nome do pescador mais antigo, daquele que sempre pescou no local. Na Sesmaria do Jardim, por exemplo, destacamos os seguintes: Poção do João Carlos, do Laguinho, do Ciro e das Neve.

14 Informação fornecida pela Dona Maria Nice Machado Aires, em entrevista realizada no dia 2 de agosto de 2018. 
Em algumas comunidades da Baixada, subsiste a prática dos mutirões ou adjuntos $^{15}$, que, no caso, se organizam em torno da quebra do coco-babaçu, coletado das palmeiras, consideradas árvores-mães ${ }^{16}$. Os mutirões ou adjuntos são realizados em momentos de precisão das famílias, quando se veem obrigadas a extrair uma maior quantidade de amêndoas para suprir as necessidades mais imediatas.

Como visto, as atividades da roça e do extrativismo são realizadas de forma autônoma, segundo um sistema de uso comum da terra, das florestas e das águas. Não obstante os limites impostos pelos domínios da propriedade da terra, elas são efetuadas livremente, condicionadas às necessidades e à capacidade de trabalho de cada unidade familiar.

As práticas de uso comum, que envolvem o saber tradicional dos moradores das comunidades sobre os ciclos naturais, divididos entre verão e inverno, expressam "modelos locais de natureza” (ESCOBAR, 2016) 17, construídos como forma de garantir a reprodução física e cultural e a defesa dos territórios. Nas situações apresentadas, natureza e cultura, assim como indivíduo e comunidade, constituem partes indissociáveis de um todo ${ }^{18}$.

O cercamento das terras tradicionalmente ocupadas, incluindo os campos naturais inundáveis, por aqueles que se intitulam proprietários, desorganiza esse sistema de reprodução das comunidades, além de representar uma grave violação de direito, tipificando crimes, já que esses espaços pertencem ao patrimônio do estado e da União, ou mesmo às próprias comunidades, que receberam essas terras com a decadência e a desagregação do sistema escravista-monocultor (ALMEIDA, 1989).

Os conflitos socioambientais gerados pela apropriação ilegal das terras mostram a face violenta dos processos em curso desde o final dos anos 1980 do século XX. Eles devastam a biosfera e expulsam da região essas comunidades, que, ao longo das décadas, construíram uma maneira própria de recuperar, de manter os ritmos e fluxos e de cuidar da natureza, desgastada pela intensa exploração agrícola do sistema monocultor exportador.

15 "Mutirões" ou "adjuntos" são os termos utilizados pelas comunidades para expressar na região formas de trabalho que envolvem ajuda mútua. Em outros locais do Brasil, outras palavras são empregadas, como "puxirão", no Paraná. Sobre a origem das formas de ajuda mútua no país, consultar Caldeira (1956).

16 As reflexões sobre as palmeiras de babaçu como árvores-mães podem ser vistas em Shiraishi Neto (2017a). Tal ideia aproxima-se do que foi denominado "ecofeminismo" (MIES; SHIVA, 1993).

17 O trabalho de Fernando Coronil (2016) sobre a representação da natureza em um mundo globalizado revela a concepção de um modelo atrelado aos interesses do mercado financeiro. Referido trabalho serviu de fonte de inspiração para as reflexões sobre o papel do direito ambiental no Brasil, que constrói uma representação (SHIRAISHI NETO, 2017b).

18 A pesquisa de Prado (2007) sobre as festas em dois municípios da Baixada esclarece como esses grupos sociais organizam as suas maneiras de ser e de fazer. 
Vale sublinhar que, mesmo nas áreas designadas como "terras altas", o uso generalizado do fogo, de tratores e de correntes desmata, limpa e mata toda sorte de vida, para o plantio do capim e a criação de gado. Tais procedimentos sinalizam a velocidade e a dimensão dos danos socioambientais. "Terra morta, água morta", título do último capítulo de Sassen (2015), encontra similitude com a tragédia das situações vividas na região da Baixada Ocidental: "Acabam com tudo... enquanto que nos campos naturais inundáveis acabam com os peixes e as águas, nas 'terras altas', o mato" (informação verbal) ${ }^{19}$. O relato de dona Maria Nice expressa a percepção, o sentimento de que os recursos naturais estão ficando cada vez mais escassos; daí sua luta e a dos seus "companheiros" pela criação da Reserva Extrativista Enseada da Mata.

\section{BÚFALOS E CERCAS ELÉTRICAS: NATURALIZAÇÃO DOS DISPOSITIVOS DE VIOLÊNCIA}

Nas conversas, as lideranças foram uníssonas em afirmar que, hoje em dia, é possível observar a criação de búfalos e de cercas em toda a região da Baixada. As cercas elétricas começaram a ser instaladas em período recente. Enquanto na década de 1990 do século XX não se fazia alusão ao uso desse dispositivo de segurança, a partir de 2000, tornaram-se corriqueiros os relatos de acidentes causados pelas cercas elétricas.

Desde a época em que foram introduzidos na região, os búfalos são criados soltos nos campos naturais inundáveis, espalhando medo entre os moradores das comunidades, que vivem sob ameaça, sofrendo carreiras e ataques dos bichos.

As informações não são precisas sobre a data da introdução desses animais na região da Baixada Ocidental Maranhense. Segundo Muniz (2009), isso ocorreu no período do governo José Sarney (1966-1969), como parte do conjunto de estratégias de modernização da agricultura do estado, tida como atrasada, já que baseada na unidade familiar de produção camponesa ${ }^{20}$.

A introdução da bubalinocultura na Baixada Maranhense se deu na segunda metade dos anos 1960, teve o apoio do Governo Estadual, visando o desenvolvimento econômico para a região. Porém não houve um planejamento que permitisse prever os impactos sociais e ambientais da introdução do animal em um ambiente ecologicamente sensível, com predominância da atividade da pesca, da caça e da agricultura de subsistência. A maior preocupação com o empreendimento foi o fator econômico, não foi levando em consideração

19 Informação fornecida pela Dona Maria Nice Machado Aires, em entrevista realizada no dia 2 de agosto de 2018.

20 Para um retrato do Maranhão pelo governo Sarney, recomendamos o documentário Maranhão 66, dirigido por Glauber Rocha (MARANHÃO66, [1969?]). 
as populações que vivem e se mantêm naquele território e dos recursos nele existentes (MUNIZ, 2009, p. 22, grifo nosso).

Por seu tamanho, os búfalos assoreiam os campos inundáveis, tornandoos impróprios, uma vez que a água fica suja, podre e fedorenta, segundo relatos. Além disso, comem os peixes e os pequenos animais, ameaçando todo o ecossistema aquático da região, cuja preservação é vital para a quantidade e a qualidade dos peixes e das aves migratórias ${ }^{21}$, que se deslocam em determinados períodos do ano, ocupando as extensas porções de terras alagadas, formadas por lagos e rios.

Os problemas decorrentes da criação dos búfalos nos campos naturais inundáveis atingem não só o frágil ecossistema, mas também os moradores das comunidades, que, de uma forma ou de outra, sofrem as consequências diretas do manejo inadequado. Dona Maria do Rosário Soares Ferreira, em entrevista realizada no dia 23 de julho de 2016, revelou-nos que o seu filho mais novo, conhecido como Bebero, teve sérias doenças de pele por causa do contato com as águas contaminadas por dejetos de búfalos. O diagnóstico foi feito após o alastramento de uma série de manchas brancas pelo corpo do garoto. Ele foi tratado por dermatologistas em São Luís e passou por diversos constrangimentos no período do tratamento, devido às marcas da doença que ficaram no seu corpo. A família arcou com todos os custos do tratamento - exames e medicação.

Isso tudo tem gerado uma espécie de guerra contra os búfalos, relatada em conversas, entrevistas, denúncias, audiências, ações judiciais e pesquisas. Algumas comunidades passaram a se organizar para enfrentar o problema, chegando a retirar à força os búfalos de seus territórios. Em entrevista realizada no dia 16 de junho de 2005, Edinaldo Padilha, conhecido como Cabeça, revelou que a comunidade quilombola de Camaputiua, localizada no município de Cajari, vizinho ao município de Penalva, diante de tantos problemas com os búfalos e das permanentes violações de direitos, viu-se na obrigação de resistir quando vários búfalos foram mortos.

Em 1989, a Constituição do Estado do Maranhão dispôs sobre a retirada dos búfalos da região da Baixada no artigo 46 do Ato das Disposições Constitucionais Transitórias. Contudo, imediatamente após a sua promulgação, o seu conteúdo foi alterado, sendo acrescidos os parágrafos $1 .^{\circ}, 2 .^{\circ}$ e $3 .^{\circ}$, mediante a Emenda Constitucional n. ${ }^{\circ}$ 5, de 3 de outubro de 1991 (MARANHÃO, 1991b).

\footnotetext{
21 A reportagem do programa Repórter Mirante (REPÓRTER..., 2021) destaca problemas recentes, provocados pelo aumento do número de biguás, que se deslocam do Pantanal para a região por causa das queimadas. Famintas e cansadas, essas aves disputam os peixes com os pescadores artesanais.
} 
Essa manobra parlamentar praticamente inviabilizou o cumprimento do referido artigo, já que condicionou a retirada dos búfalos ao julgamento dos processos discriminatórios judiciais e administrativos em curso no Poder Judiciário e no Instituto de Colonização e Terras do Maranhão (Iterma).

O problema é que o próprio governo - na hipótese, o Iterma - desconhece a existência e a situação de todos esses processos, ajuizados ainda nas décadas passadas, entre 1970 e 1980. O processo discriminatório do município de Matinha, por exemplo, estava, segundo técnicos do órgão, perdido no Iterma.

No município de Penalva, vários tomos do processo judicial não estavam no cartório, mas na residência da escrivã, ironicamente também perdidos. As várias ações iniciadas ou ajuizadas já foram julgadas, restando a sua execução judicial. No entanto, a execução das ações implica uma outra ordem de problemas, talvez mais graves e desafiadores para o governo, pois boa parte das terras devolutas do estado foi transferida ilegalmente a terceiros, que reivindicam o seu domínio.

A aquisição das terras é seguida do açambarcamento de porções muito maiores no lote originariamente adquirido, avançando sobre as terras livres da região da Baixada, isto é, as terras tradicionalmente ocupadas pelas comunidades - essas últimas, como descrito acima, fruto de compra, doação ou abandono das terras pelos grandes proprietários diante da decadência e da desagregação do sistema escravista-monocultor.

O cercamento das terras, inclusive por meio do uso de cercas elétricas, consiste no terceiro ato de violência daqueles que se intitulam proprietários. Assusta, entretanto, a naturalidade como é tratado o uso desse tipo de tecnologia, já que essas cercas existem em quase todos os municípios da região.

As cercas elétricas são consideradas, pelos pretensos proprietários, a forma mais eficiente, pois conseguem segurar mais os moradores, impedindo sua passagem. As cercas de arame, por sua vez, não impedem sua entrada, podendo ser cortadas ou mesmo dribladas, isto é, ultrapassadas facilmente. Qualquer tentativa de transposição das cercas elétricas gera medo, ferimentos graves e até mortes, como foi relatado. Dona Núbia Mendes, em entrevista realizada em 24 de agosto de 2016, afirmou que, quando estava grávida, chegou a tomar um choque em uma cerca eletrificada. Ela ressaltou: "o perigo é maior quando o campo está cheio de água encobrindo as cercas, qualquer desatento pode sofrer uma descarga de energia e morrer" (informação verbal) ${ }^{22}$. Driblar as cercas e correr dos búfalos criados soltos nos campos naturais inundáveis fazem parte da rotina dos moradores, que se veem ameaçados.

22 Informação fornecida pela Dona Núbia Mendes, em entrevista realizada no dia 24 de agosto de 2016. 
Do ponto de vista ambiental, as cercas também acarretam danos que incidem na vida das comunidades. Com cercamento, uma vegetação floresce nos campos, uma espécie de algodão nativo, que se alastra, juntamente com o capim, sobre os campos naturais inundáveis, enrolando-se nas cercas. Os espinhos do algodão dificultam ainda mais o acesso aos locais de pesca.

O descontrole do algodão e do capim, que se esparramam sobre os campos, dificulta a realização das atividades da pesca artesanal. Por isso, algumas práticas estão se perdendo, como a pesca de tarrafa e da rede. Outras maneiras de pescar, como o choque e a pudica, mantêm-se, embora com muitas dificuldades, diante das situações que colocam em risco o próprio ecossistema da região da Baixada.

Aparentemente, o uso das cercas elétricas tem um duplo aspecto de força: além de impedir o livre trânsito dos moradores das comunidades pelo território tradicionalmente ocupado, visa também reter esses moradores num determinado espaço geográfico, geralmente limitado à moradia. Na Sesmaria do Jardim, em Matinha, as famílias estão literalmente confinadas em suas casas.

Para além dos aspectos ligados à mobilidade e à fragmentação dos territórios, a construção das cercas elétricas revela o seu lado violento, de destruição das relações socioespaciais entre os moradores das comunidades, baseadas em laços de solidariedade e de reciprocidade, na medida em que tenta instituir uma outra relação, inclusive com os próprios territórios tradicionalmente ocupados, incluindo os campos naturais inundáveis.

Diante do cercamento generalizado das terras, que fragmenta e hierarquiza a produção dos espaços, vale a pena recuperar os estudos sobre os processos coloniais na África, pois eles permitem compreender a lógica da violência. Bourdieu e Sayad (2017) analisam as políticas coloniais que expulsam, deslocam e reagrupam os camponeses de modo a mantê-los controlados e distantes dos rebeldes independentistas na Argélia. A desagregação provocada por essas políticas, aparentemente legal, já que fundamentada em leis agrárias, servia para promover a apropriação das terras pelos colonos franceses, cujo pretexto era modernizar a agricultura daquele país, tido como economicamente atrasado.

Aliás, esse discurso do atraso e da modernização também foi adotado para justificar a introdução dos búfalos e os cercamentos das terras na região em estudo. O uso das cercas elétricas provocou a mobilização das comunidades, como a Sesmaria do Jardim, para cobrar do governo a sua retirada nos campos (informação verbal) ${ }^{23}$.

23 Informação fornecida por Maria do Rosário Soares Costa Ferreira, em entrevista realizada no dia 8 de agosto de 2018 . 
As insistentes denúncias da comunidade Sesmaria do Jardim contra o cercamento ilegal dos campos, que incluíram reuniões e ocupação do Iterma, obrigaram o governo a organizar o que ficou conhecido como Operação Baixada Livre ${ }^{24}$. A operação abrangeu as Secretarias de Estado da Agricultura Familiar (SAF), dos Direitos Humanos e Participação Popular (Sedihpop), do Meio Ambiente e Recursos Hídricos (Sema), o Iterma e o Batalhão Ambiental de Polícia Militar para a retirada das cercas. O envolvimento de tantas Secretarias de Estado sinaliza a complexidade da operação diante dos abusos e das ilegalidades cometidas, como o furto de energia elétrica.

Em Anajatuba, outro município da região, também ocorreu a Operação Baixada Livre. Lá, isso se deu em razão dos conflitos, que resultaram em uma ordem de prisão contra vários pescadores, acusados de crime de desobediência judicial, nos autos de uma ação de interdito proibitório, proposto pelos pretensos proprietários. A ação visava inibir as tentativas dos pescadores de derrubar na marra as cercas, que impediam o acesso aos locais de pesca nos campos naturais inundáveis.

Houve várias reuniões intermediadas pela Sedihpop e pela SAF e um parecer jurídico elaborado pela Sedihpop, em conjunto com outras secretarias, o que serviu de subsídio às ações conjuntas do governo na resolução dos problemas. Em vários municípios da região, o Ministério Público Estadual foi acionado pelas mais diversas comunidades, e algumas denúncias e ações civis públicas foram propostas pelo Parquet, ainda sem resultados efetivos.

\section{PRIVATIZAÇÃO DOS USOS DAS ÁGUAS: FORMAS DE REPRESAMENTO PARA A MELHORIA DA PRODUÇÃO}

O gado, os búfalos e as cercas, além de produzirem a devastação da biosfera, gerando brutalidades, expulsam os moradores das comunidades por meio da perda dos usos tradicionais de seus territórios. Isso os tem impelido a se deslocarem para as chamadas pontas de rua dos povoados e das cidades, como é o caso do bairro Novo, na cidade de Penalva, que era uma cabeceira da Enseada da Mata, exemplo mais recente das consequências dos processos de modernização

24 O governo do estado do Maranhão admite a gravidade das cercas elétricas, pois acarretam problemas socioambientais à região da Baixada Ocidental Maranhense. O levantamento preliminar das cercas elétricas, realizado pelo próprio estado, revela a extensão e a gravidade dos fatos. Segundo esses dados preliminares, existem cercas elétricas nos seguintes municípios: Anajatuba, Arari, Bela Vista do Maranhão, Cajari, Igarapé do Meio, Matinha, Monção, Olinda Nova do Maranhão, Palmeirândia, Peri-Mirim, Pinheiro, São Bento, São Vicente de Ferrer, Viana e Vitória do Mearim. 
da região. Por outro lado, a tensão gerada pelos cercamentos das terras livres tem sido diluída em razão do aliciamento de jovens para o trabalho nas lavouras e na construção civil em outras regiões do país. Fora das comunidades, esses jovens acabam por se distanciar momentaneamente dos conflitos.

A essa gama de conflitos, somam-se mais recentemente as formas de represamento das águas, outro grave problema, pois, além de impactar o frágil ecossistema da Baixada, modificando o fluxo hidrológico e ameaçando os ciclos naturais, priva os moradores das comunidades tradicionais do acesso e do uso comum das fontes, dos rios e das nascentes. A construção de barragens nos rios e lagos pelos governos municipais e estadual, como em Penalva e Viana, tem alterado o ecossistema da região.

Os açudes construídos pelos pretensos proprietários, destinados à piscicultura, e, mais recentemente, à carcinicultura, que tem sido estimulada pelo governo ${ }^{25}$, são uma outra forma de represamento e de "privatização" das águas. Essa maneira de uso das águas interrompe os fluxos naturais e sociais, na medida em que, como lógica de produção, as águas são apropriadas individualmente visando o mercado regional, já que os peixes criados em cativeiro não são apreciados pelos moradores das comunidades, que preferem os peixes naturais pescados nos campos inundáveis de modo tradicional, por meio de instrumentos inventados consoante um saber prático desenvolvido ao longo das décadas. Os instrumentos de pesca não se restringem à rede e ao anzol, incluem um conjunto de artefatos.

Os extensos dutos e encanamentos que atravessam as terras altas, ligando os lagos, fontes e nascentes aos açudes, expõem a forma de "privatização" das águas e revelam a falta de controle do Estado sobre os usos desse precioso recurso. As águas, que são puxadas ilegalmente, sem qualquer tipo de autorização e de fiscalização dos órgãos dos governos, têm provocado graves problemas, como a constante falta de água para as comunidades devido ao bloqueio dos acessos, e a seca dos lagos, das fontes e das nascentes, que se estende, em alguns locais, por um longo período do ano, resultante da canalização indiscriminada das águas para abastecer os açudes privados.

25 Recentemente, o governo do estado sancionou uma lei que regulamenta a carcinicultura no Maranhão. Segundo informações, a Lei aprovada tem problemas técnicos, inclusive de constitucionalidade, sobretudo no tocante à competência, e mesmo assim foi aprovada. Pelo visto, a Lei atende interesses econômicos do setor de carcinicultura, que migraram para o Maranhão, diante dos problemas enfrentados em outros estados do Nordeste. Sobre os problemas decorrentes da carcinicultura, ver a carta aberta (COMITÊ DE DEFESA DOS CAMPOS NATURAIS DE SANTA RITA E DA BAIXADA MARANHENSE, 2018) assinada por diversas entidades e movimentos sociais. 


\section{CONSIDERAÇÕES FINAIS}

Pelo visto, há uma ofensiva do capital sobre a região da Baixada em razão de seu potencial econômico. Essa ofensiva manifesta-se de diversas formas e incide diretamente nas maneiras de viver das comunidades. Um exemplo são os cercamentos, que constituem não simples cercas para delimitar uma porção de terra, mas dispositivos que amedrontam e colocam em risco a vida de todos os moradores. As iniquidades praticadas - aqui descritas - a pretexto de desenvolver a região da Baixada Ocidental Maranhense, reconhecida como sítio Ramsar desde 2000, são fortes indicativos do "racismo ambiental", que gera e agrava as injustiças.

Antes abundantes e de acesso livre, as águas passaram a correr nos canos, aprisionadas nas represas e nos açudes, agora elas têm dono. Essa forma de gerenciamento da terra e das águas tem mudado a paisagem da região, que se transforma em terra morta, água morta.

Diante das ofensivas, as comunidades não têm ficado passivas, reivindicando “justiça ambiental”, até porque todo o conjunto de suas ações visa garantir a continuidade de sua reprodução física e cultural. No caso, observa-se que a perda dos territórios tradicionalmente ocupados e o "abandono" de determinadas práticas socioambientais, decorrentes do cercamento ilegal das terras, têm sido acompanhados de uma maior tomada de consciência da questão identitária, que coloca em questão o modelo de desenvolvimento imposto à região.

Tais processos de mobilização vividos pelas comunidades produzem novas relações, que se expressam da seguinte maneira: novo senso de pertencimento ao lugar, novos laços de solidariedade entre os membros das comunidades, novas relações entre as comunidades e o estabelecimento de novos interlocutores, destacando-se, no âmbito federal, o Incra, a Fundação Cultural Palmares (FCP) e o ICMBio e, no âmbito do estado do Maranhão, a Comissão Quilombola do Iterma.

Os resultados preliminares da pesquisa apontam o fortalecimento das identidades em construção e o domínio de uma pauta étnica nas agendas políticas com os governos, a exemplo da reivindicação ao governo de criação do Iterma Quilombola. Em vários municípios da Baixada, há um processo de mobilização dessas comunidades, que se organizam em associações para lutarem por direitos que estão sob grave ameaça. Essa tendência de mobilização, ancorada nos lugares e articulando várias escalas, contrapõe-se às experiências anteriores de organização, mas não as elimina. 


\section{REFERÊNCIAS}

ABREU, S. F. Na Terra das Palmeiras: estudos brasileiros. Rio de Janeiro: Officina Industrial Graphica, 1931.

ACSELRAD, H. Justiça ambiental: ação coletiva e estratégias argumentativas. In: ACSELRAD, H.; HERCULANO, S.; PÁDUA, J. A. (org.). Justiça ambiental e cidadania. Rio de Janeiro: Relume Dumará, 2004. p. 23-39.

ACSELRAD, H.; HERCULANO, S.; PÁDUA, J. A. A justiça ambiental e a dinâmica das lutas socioambientais no Brasil: uma introdução. In: ACSELRAD, H.; HERCULANO, S.; PÁDUA, J. A. (org.). Justiça ambiental e cidadania. Rio de Janeiro: Relume Dumará, 2004. p. 9-20.

ALMEIDA, A. W. B. Terras de preto, terras de santo, terras de índio: uso comum e conflito. Cadernos do NAEA, Belém, n. 10, p. 163-196, 1989.

ALMEIDA, A. W. B.; MOURÃO, L. Questões agrárias no Maranhão contemporâneo. Pesquisa Antropológica, Brasília, n. 9-10, p. 1-27, 1976.

ALMEIDA, A. W. B.; SHIRAISHI NETO, J.; MARTINS, C. C. Guerra ecológica nos babaçuais: o processo de devastação dos palmeirais, a elevação do preço de commodities e o aquecimento do mercado de terras na Amazônia. São Luís: Lithograf, 2005.

ANDRADE, M. P. Terra de índio: identidade étnica e conflitos em terras de uso comum. São Luís: EDUFMA, 1999.

ANDRADE, M. P. Gás, fumaça e zoada: laudo antropológico sobre impactos das usinas termoelétricas do Complexo Parnaíba para populações tradicionais. São Luís: EDUFMA, 2017.

BOURDIEU, P.; SAYAD, A. El desarraigo: la violencia del capitalismo en una sociedad rural. Buenos Aires: Siglo XXI, 2017.

BRASIL. Ministério do Meio Ambiente. Secretaria de Biodiversidade e Florestas. Gerência de Biodiversidade Aquática e Recursos Pesqueiros.

Sítio Ramsar. APA da Baixada Ocidental Maranhense-MA. Planejamento para o Sucesso de Conservação. Brasília, DF, [entre 2007 e 2010].

Disponível em: https://antigo.mma.gov.br/publicacoes/biodiversidade/ category /53-biodiversidade-aquatica.html?download $=1148: \mathrm{s} \% \mathrm{C} 3 \%$ ADtioramsar-apa-da-baixada-maranhense-ma-planejamento-para-o-sucesso-deconserva \%C3\%A7\%C3\%A3o\&start=20. Acesso em: 25 jul. 2018.

BRASIL. Ministério do Meio Ambiente. Sítios Ramsar. Brasília, DF, [2018?]. Disponível em: http://www.mma.gov.br/areas-protegidas/instrumentos-degestao/s\%C3\%ADtios-ramsar. Acesso em: 3 ago. 2018. 
BRASIL. Presidência da República. Decreto n. ${ }^{\circ}$ 1.905, de 16 de maio de 1996. Promulga a Convenção sobre Zonas Úmidas de Importância Internacional, especialmente como Habitat de Aves Aquáticas, conhecida como Convenção de Ramsar, de 02 de fevereiro de 1971. Diário Oficial da União: seção 1, Brasília, DF, p. 8520, 17 maio 1996. Disponível em: http:/ /www.planalto.gov. br/ccivil_03/decreto/1996/D1905.htm. Acesso em: 3 ago. 2018.

BRITO, C. S. Bem viver e povos e comunidades tradicionais no Brasil: o processo de regularização fundiária do território tradicional Sesmaria do Jardim, Baixada Maranhense. 2018. Dissertação (Mestrado em Agriculturas Amazônicas) - Programa de Pós-Graduação em Agriculturas Amazônicas, Universidade Federal do Pará, Belém, 2018.

BULLARD, R. D. Dumping in Dixie: race, class, and environmental quality. 3. ed. New York: Westview Press, 2000.

BULLARD, R. D. Enfrentando o racismo ambiental no século XXI. In: ACSELRAD, H.; HERCULANO, S.; PÁDUA, J. A. (org.). Justiça ambiental e cidadania. Rio de Janeiro: Relume Dumará, 2004. p. 41-68.

BUTLER, J. Quadros de guerra: quando a vida é passível de luto? Rio de Janeiro: Civilização Brasileira, 2017.

CALDEIRA, C. Mutirão: formas de ajuda mútua no meio rural. São Paulo: Companhia Editora Nacional, 1956.

CARVALHO, H. M. Da aventura à esperança: a experiência autogestionária no uso comum da terra. Curitiba: [s. n.], 1984. Mimeografado.

COELHO, E. M. B.; ALMEIDA, M. R. M. Dinâmicas das lutas por reconhecimento étnico no Maranhão. In: REUNIÃO BRASILEIRA DE ANTROPOLOGIA, 31., 2018, Brasília, DF. Anais [...].

Brasília, DF: UnB, 2018. p. 1-17. Disponível em: http:/ /www. evento.abant.org.br/rba/31RBA/files/1540931986_ARQUIVO_ DINAMICASDASLUTASPORRECONHECIMENTOETNICONO MARANHAO2018.pdf. Acesso em: 5 maio 2021.

COMITÊ DE DEFESA DOS CAMPOS NATURAIS DE SANTA RITA E DA BAIXADA MARANHENSE. Carta aberta ao povo de Santa Rita e do Maranhão. Contra a implantação de empresas de criação de camarão nos campos naturais de Santa Rita e na Baixada Maranhense. Pela preservação dos campos naturais de Santa Rita e da Baixada Maranhense. Santa Rita: Comitê de Defesa dos Campos Naturais de Santa Rita e da Baixada Maranhense, 11 jun. 2018. Disponível em: http:/ /nmpsaoluis.com/wp-content/uploads/2018/06/ Carta-Aberta-Campos-de-Santa-Rita-Aprovada-com-apoiamentos.pdf. Acesso em: 28 jun. 2018. 
CORONIL, F. Naturaleza del poscolonialismo: del eurocentrismo al globocentrismo. In: LANDER, E. (Ed.). La colonialidad del saber: eurocentrismo y ciencias sociales, perspectivas latinoamericanas. Buenos Aires: Fundación CICCUS, 2016. p. 105-125.

ESCOBAR, A. La invención del desarrollo. Popayan: Universidad del Cauca, 2012.

ESCOBAR, A. El lugar de la naturaleza y la naturaleza del lugar: ¿globalización o postdesarrollo? In: LANDER, E. (Ed.). La colonialidad del saber: eurocentrismo y ciencias sociales, perspectivas latinoamericanas. Buenos Aires: Fundación CICCUS, 2016. p. 131-161.

FLORIANI, D. Natureza da ética e ética da natureza: pensar, fazer, subjetivar, julgar e decidir no socioambientalismo. Curitiba: [s. n.], 2017. Mimeografado.

LOPES, R. Uma região tropical. Rio de Janeiro: Cia. Editora Fon-Fon e Seleta, 1970.

MARANHÃO 66. Direção: Glauber Rocha. Produção: Luiz Carlos Barreto. [S. l.: s. n.], [1969?]. 1 vídeo (10 min). Disponível em: https://www.youtube.com/ watch?v=t0JJPFruhAA. Acesso em: 8 ago. 2018.

MARANHÃO. Decreto No 11.900, de 11 de junho de 1991. CRIA, no Estado do Maranhão, a Área de Proteção Ambiental da Baixada Maranhense [...]. São Luís: Governo do Estado, [1991a]. Disponível em: http://oads.org.br/ leis/2192.pdf. Acesso em: 8 ago. 2018.

MARANHÃO. Emenda Constitucional Nº 005/91. ALTERA e acrescenta dispositivos ao Ato das Disposições Constitucionais Transitórias da Constituição Federal. São Luís: Assembleia Legislativa do Maranhão, [1991b]. Disponível em: http://stc.ma.gov.br/legisla-documento/?id=2185. Acesso em: 8 ago. 2018.

MIES, M.; SHIVA, V. Ecofeminismo. Lisboa: Instituto Piaget, 1993.

MUNIZ, L. M. A matança de búfalos na Baixada Maranhense: as consequências de um projeto de desenvolvimento e o conflito socioambiental. 2009. Dissertação (Mestrado em Ciências Sociais) - Programa de PósGraduação em Ciências Sociais, Universidade Federal do Maranhão, São Luís, 2009.

O’DWYER, E. C. Prefácio. In: SÁ, L. M. O pão da terra: propriedade comunal e campesinato livre na Baixada Ocidental Maranhense. São Luís: EDUFMA, 2007. p. 17-22. 
PEDRO, V. V.; SANT'ANA JÚNIOR, H. A. “Na lei ou na marra nós vamos ganhar": a judicialização como estratégia de confronto político pela defesa do Cajueiro e seu território étnico. In: SANT'ANA JÚNIOR, H. A.; TEISSERENC, M. J. S. A.; BRUSTOLIN, C. (org.). Desenvolvimento em questão: projetos desenvolvimentistas, resistências e conflitos socioambientais. São Luís: EDUFMA, 2018. p. 117-153.

PLANETA en venta. Direção: Alexis Marant. Produção: Guylaine Loquet e Jean Paul Billault. [S. l.: s. n.], 2017. 1 vídeo (56 min). Disponível em: https:/ / www.youtube.com/watch?v=nka_Ri0avKQ. Acesso em: 7 set. 2018.

PRADO, R. P. S. Todo ano tem: as festas na estrutura social camponesa. São Luís: EDUFMA, 2007.

REPÓRTER Mirante mostra as belezas e os contrastes naturais da Baixada Maranhense. [S. l.: s. n.], 2021. Publicado pelo canal William Amorim.

Disponível em: https://www.youtube.com/watch?v=iQKt7ja9k-8. Acesso em: 3 maio 2021.

SÁ, L. M. O pão da terra: propriedade comunal e campesinato livre na Baixada Ocidental Maranhense. São Luís: EDUFMA, 2007.

SASSEN, S. Expulsiones: brutalidad y complejidad en la economía global. Buenos Aires: Katz Editores, 2015.

SHIRAISHI NETO, J. Estudo da situação fundiária para criação da Reserva Extrativista Enseada da Mata, município de Penalva, MA. São Luís: [s. n.], 2011. Mimeografado.

SHIRAISHI NETO, J. Quebradeiras de coco: "Babaçu Livre" e as Reservas Extrativistas. Revista Veredas, Belo Horizonte, v. 14, n. 28, p. 147-166, jan./ abr. 2017 a.

SHIRAISHI NETO, J. Globalização do direito: novos conteúdos à natureza.

Revista Internacional de Direito Ambiental, Caxias do Sul, RS, v. 6, n. 17, p. 117-140, maio/ago. 2017b.

SHIVA, V. Resources. In: SACHS, W. (Ed.). The development dictionary: a guide to knowledge as power. New York: Zed Books, 2005. p. 206-218.

VALVERDE, O. Geografia econômica e social do babaçu no Meio Norte.

Separata da Revista Brasileira de Geografia, Rio de Janeiro, n. 4, p. 381-419, out./dez. 1957.

VELHO, O. G. Frente de expansão e estrutura agrária. Rio de Janeiro: Zahar, 1981. 